\title{
PM Wind Generator Topologies
}

\author{
Yicheng Chen, Pragasen Pillay, Fellow, IEEE, and Azeem Khan, Student Member, IEEE
}

\begin{abstract}
The objective of this paper is to provide a comparison among permanent magnet (PM) wind generators of different topologies. Seven configurations are chosen for the comparison, consisting of both radial-flux and axial-flux machines. The comparison is done at seven power levels ranging from 1 to $200 \mathrm{~kW}$. The basis for the comparison is discussed and implemented in detail in the design procedure. The criteria used for comparison are considered to be critical for the efficient deployment of PM wind generators. The design data are optimized and verified by finite-element analysis and commercial generator test results. For a given application, the results provide an indication of the best-suited machine.
\end{abstract}

Index Terms-Axial flux, outer rotor, permanent magnet, radial flux, wind generator.

\section{INTRODUCTION}

T O CONVERT wind power into electricity, many types of generator concepts have been used and proposed [1]. Most of the low-speed wind turbine generators presented are permanent-magnet (PM) machines. These have the advantages of high efficiency and reliability since there is no need of external excitation and conductor losses are removed from the rotor [2], [3].

Basically, PM generators can be divided into radial-flux and axial-flux machines, according to the flux direction in the air gap. Transverse flux machines exist, but do not seem to have gained a foothold in wind power generation. The availability of modern high energy density magnet materials, such as $\mathrm{NdFeB}$, has made it possible to design special topologies such as toothless stators with air gap windings [1], [2].

A comparison of generator topologies for direct-drive wind turbines has been carried out using torque density and cost/torque with respect to the machine outer diameter as the criteria [4]. Sixty different machine prototypes are compared. However, the study lacks theoretical background and the data considered deal with different requirements and situations.

Comparison of machines of different topologies is a delicate task. An analytical approach for the derivation of torque density

Paper IPCSD-05-062, presented at the 2004 Industry Applications Society Annual Meeting, Seattle, WA, October 3-7, and approved for publication in the IEEE TRANSACTIONS ON INDUSTRY APplications by the Electric Machines Committee of the IEEE Industry Applications Society. Manuscript submitted for review January 9, 2005 and released for publication August 26, 2005.

Y. Chen was with the Department of Electrical and Computer Engineering, Clarkson University, Potsdam, NY 13699 USA. He is now with Siemens Energy and Automation, Alpharetta, GA 30005 USA (e-mail: yiecheng@siemens.com).

P. Pillay is with the Department of Electrical and Computer Engineering, Clarkson University, Potsdam, NY 13699 USA (e-mail: pillayp@ clarkson.edu)

A. Khan is with the Department of Electrical Engineering, University of Cape Town, Rondebosch 7701, South Africa.

Digital Object Identifier 10.1109/TIA.2005.858261

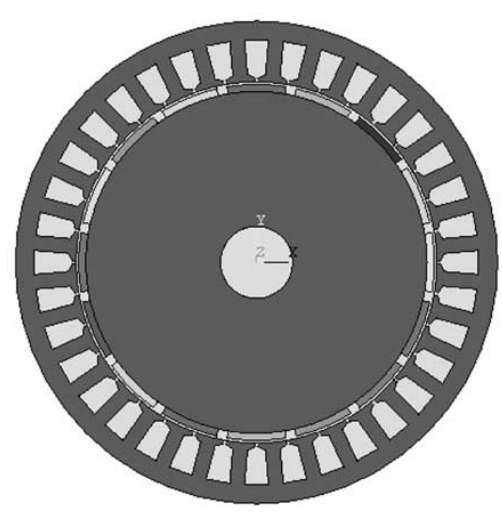

Fig. 1. Inner-rotor radial-flux construction.

and mass of active material is possible for some topologies [5], but the application is limited. An effective way to compare machine topologies is to design a large number of prototypes and obtain sufficient information to draw general conclusions. This is the method used in this paper, and optimum design is considered for each prototype.

The machine topologies considered in this study include the conventional inner-rotor radial-flux construction, outer-rotor radial-flux construction, double-stator axial-flux construction, double rotor axial-flux construction, single-sided axial-flux constructions with force balance stator and force balance rotor, and Torus toothless axial-flux construction. All the compared machines are built with surface-mounted magnets $(\mathrm{NdFeB})$ and grouped into two categories. One has direct-driven generators operating at low speeds of 50 or $100 \mathrm{r} / \mathrm{min}$; the other has the machines rotating at a high speed of $1200 \mathrm{r} / \mathrm{min}$, where gearboxes are needed. The criteria used for comparison are torque density, active material weight, outer radius, total length, total volume, and efficiency. These criteria are identified as being critical for the efficient deployment of generators in wind turbines. The basis for the comparison is highlighted to make the comparison fair and reasonable. The design equations are verified by finite-element analysis and commercial generator test results.

\section{Machine Topologies Investigated}

All the compared machines are three-phase synchronous generators.

\section{A. Conventional Inner-Rotor Radial-Flux Machine}

This is kind of a typical radial-flux generator, as shown in Fig. 1, with the PM poles rotating inside the stationary armature windings. The stator is made up of electrical grade steel laminations with distributed windings. The rotor is cylindrical 


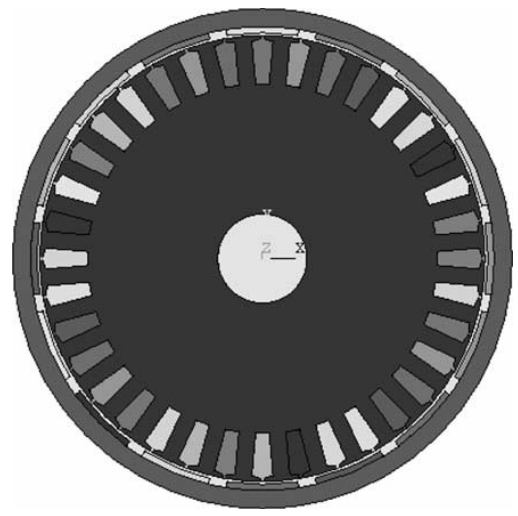

Fig. 2. Radial-flux construction with outer rotor.

in shape with a shaft on which the bearings are mounted. There are two magnets providing the magnetomotive force (MMF) required in a pair of poles, which can effectively resist the demagnetization caused by the armature reaction in a sudden short circuit. The air gap flux density is closely related to the magnet remanence and the magnet working point. It is difficult to get high air gap flux densities with low remanence magnets in this configuration.

\section{B. Radial-Flux Machine With Outer Rotor}

As illustrated in Fig. 2, the wound stator in the outerrotor configuration is stationary, located at the center of the machine, while the magnets are mounted evenly along the inner circumference of the rotating drum supported by front and rear bearings. The magnetic circuits are the same as those in the conventional inner-rotor radial-flux generator. But the blades of the wind turbine can be conveniently bolted to the front face of the drum to realize the direct coupling between the wind turbine and the PM generator. Because of the enlarged periphery of the outer-rotor drum, the multipole structure can be easily accommodated, and therefore the total length of the magnetic path is reduced. As the rotor is directly exposed to the wind, the cooling condition is improved for the magnets so that the resistance to high temperature demagnetization is enhanced.

\section{Double-Stator Slotted Axial-Flux Machine}

The layout of this type of machine is shown in Fig. 3. The shape of the stator as well as the rotor resembles a pancake, and these machines are commonly referred to as pancake machines. The machine consists of two external stators and one inner rotor. The PMs are axially magnetized and are surface mounted or inset into a cut window on the rotor disc. In all axial flux machines, the rotor rotates relative to the stator with the flux crossing the air gap in the axial direction. The stator iron core is laminated in the radial direction and resembles concentric rings that have a constant slot width and tapered teeth.

\section{Double Rotor Slotted Axial-Flux Machine}

This configuration is similar to that of the double-stator slotted axial-flux machine, except that there is one stator and two rotors. The stator is located in the middle of the two rotors

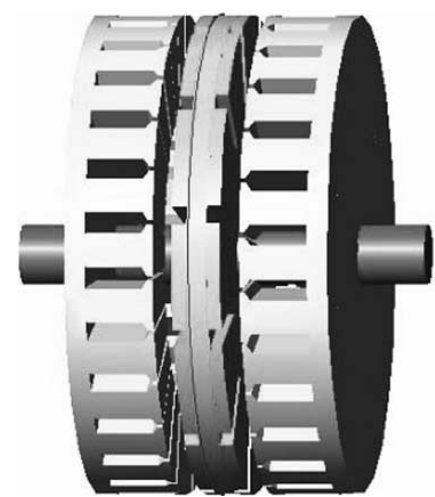

Fig. 3. Axial-flux construction with double stators.

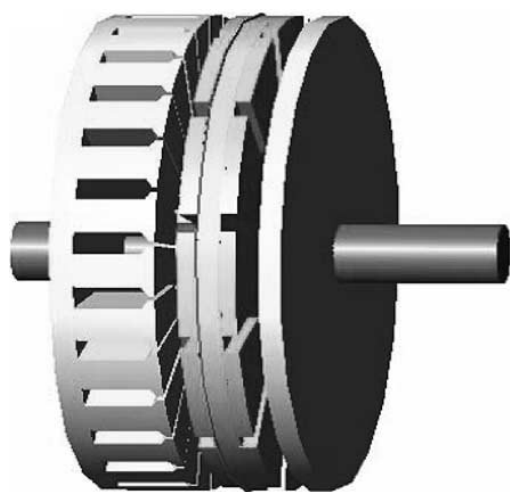

Fig. 4. Single-sided axial-flux machine with stator balance.

and slotted on both sides. An iron flux path is needed on the rotor back of yoke, but the stator back yoke can be eliminated and saved.

\section{E. Single-Sided Axial-Flux Machine With Stator Balance}

This configuration is simple, as there is only one stator and one rotor. However, a large attractive force exists between the stator and the rotor. To prevent the rotor from moving in the axial direction, a special thrust bearing must be used, which will make the construction more complicated. By adding an additional stator to the construction, an effective way is introduced in this paper to balance the attractive force, as shown in Fig. 4. On the opposite side of the rotor, PM poles are needed to produce the magnetic field necessary to induce the balance force. The stator is laminated, as the magnetic field oscillates, creating hysteresis and eddy-current losses. When the flux path is carefully designed, the force produced between the rotor and the additional stator can balance the force between the rotor and the slotted machine stator.

\section{F. Single-Sided Axial-Flux Machine With Rotor Balance}

This configuration is similar to the single-sided axial-flux machine with stator balance, except that an additional rotor with mounted magnet is added to the construction instead of a stator balance. The stator yoke length should be extended to provide a path for the magnetic field through which the balance force will be induced. An iron flux path is needed on the additional rotor 


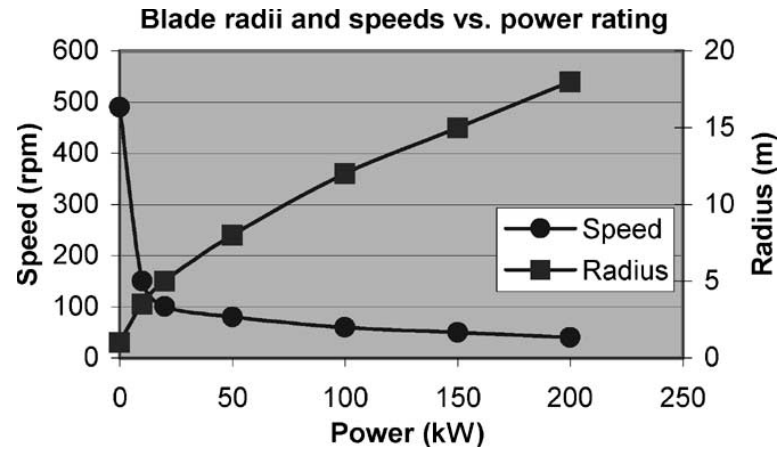

Fig. 5. Typical turbine blade radii and rated speed versus power rating.

back of yoke. Thus, this construction uses more materials than the stator balance construction.

\section{G. Axial-Flux Machine With Toroidal Winding}

This kind of prototype generator has a simple construction and is often referred to as a Torus machine. It is a slotless double-sided axial flux PM disc-typed machine. The two rotor discs are made of mild steel and have surface-mounted PMs to produce an axially directed magnetic field in the machine air gaps. The machine stator comprises a slotless toroidally wound strip-iron core that carries a three-phase winding in a toroidal fashion by means of concentrated coils. The coils have a rectangular shape according to the core cross section. The axially directed end-winding lengths are relatively short, yielding low resistance and reduced power loss. The active conductor lengths are the two radial portions facing the magnets, the polarities of which are arranged to induce additive electromotive forces (EMFs) around a stator coil.

\section{BASIS FOR COMPARISON}

In general, most modern three-bladed direct-drive horizontal axis wind turbines (HAWTs) are designed to operate at maximum aerodynamic efficiency. The radius of the turbine blades and the rated speed can be determined as a function of the output power, as illustrated in Fig. 5.

To make the comparison fair and reasonable, several parameters are kept constant or changeable in a limited range. All the machines are designed using $220 \mathrm{~V}$ as the rated phase voltage, and the power factor is kept at 0.9 , which is commonly used for wind generators. The following power ratings are chosen: 1,10 , $20,50,100,150$, and $200 \mathrm{~kW}$ for the output power. The rated speed is chosen to be $100 \mathrm{r} / \mathrm{min}$ for machines below and equal $50 \mathrm{~kW}$, and $50 \mathrm{r} / \mathrm{min}$ for machines above $50 \mathrm{~kW}$. These speeds are typical for direct-drive stand-alone generators. As large turbines have low speed, the designed rated speeds decrease with an increase in power rating. The 1200-r/min machines with gearboxes are also designed for these configurations and have a design frequency output of $60 \mathrm{~Hz}$. Since there exists large discrepancies in operating conditions between directdrive stand-alone machines and grid-connected machines, the comparison will be made separately, divided into two groups.

The number of poles is fixed at 6 for $1200-\mathrm{r} / \mathrm{min}$ machines and will change according to the design requirements for low-

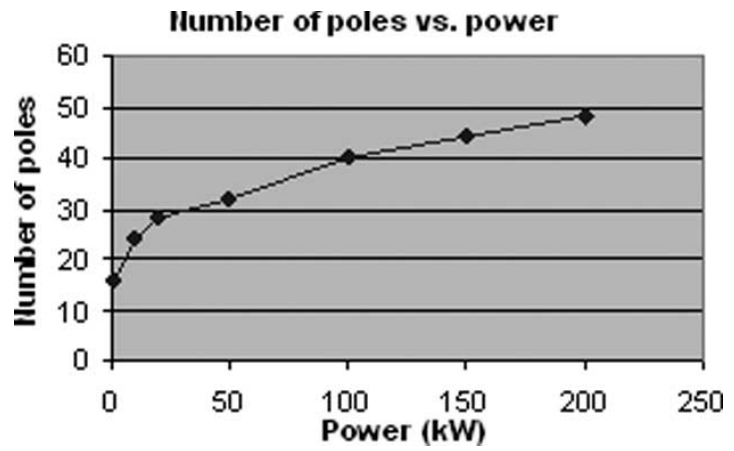

Fig. 6. Number of poles versus power rating.

speed machines. It is well known that the speed of a synchronous machine is closely related to the armature EMF frequency $f$, number of pole pairs $p$, and thus indirectly to the armature diameter $D$ and the pole pitch $\tau$ by the formula

$$
n=\frac{60 f}{p}=\frac{120 f \tau}{\pi D} \text {. }
$$

Usually, the frequency for direct-drive wind generators is changeable within a fixed range of 10 to $60 \mathrm{~Hz}$. It is evident from (1) that an effective way to have low speed is to increase the number of pole pairs. That requires, however, an increase of the armature diameter or reduction of the pole pitch or application of both these means. Enlargement of the armature diameter means enlargement of the overall volume and increase of the cost, which is undesirable. On the other hand, the pole pitch reduction meets the feasibility limit since the armature teeth become too narrow and the small slot width to depth ratio reduces the slot fill factor and increases slot leakage. Additionally, the short coil overhangs make singlelayer winding almost unworkable and complicates a doublelayer construction. Therefore, the number of poles must be chosen to match the design requirements. Fig. 6 shows the change in number of poles with respect to power ratings.

The slot fill for all the slotted machines is kept constant with a very small variation for each of the power ratings. The slotless machines have different slot fills, but they are made consistent with the values obtained for each of the different ratings. The slot fill is calculated with a fixed slot insulation thickness and using square cross-sectional wire even though the actual wire being used is circular.

The ratio of outer radius to inner radius for the axial-flux machine is chosen to be 2.5 , which is the optimum value for this research, being different from the suggested value of $\sqrt{3}$ in [7], as the small ratio will result in a large outer radius.

The tooth and yoke flux densities are kept constant with some small variations of around $1.5 \mathrm{~T}$ for all the designs. This value allows better use of the lamination steel. The air gap flux density will change to obtain the optimum design.

The air gaps are increased with an increase of the output power rating to accommodate the mechanical clearance, as larger output powers require larger stator and rotor diameters. The thickness of magnets is chosen to make the magnet working point far away from the knee point of the demagnetizing curve to prevent the magnets from demagnetization at all 


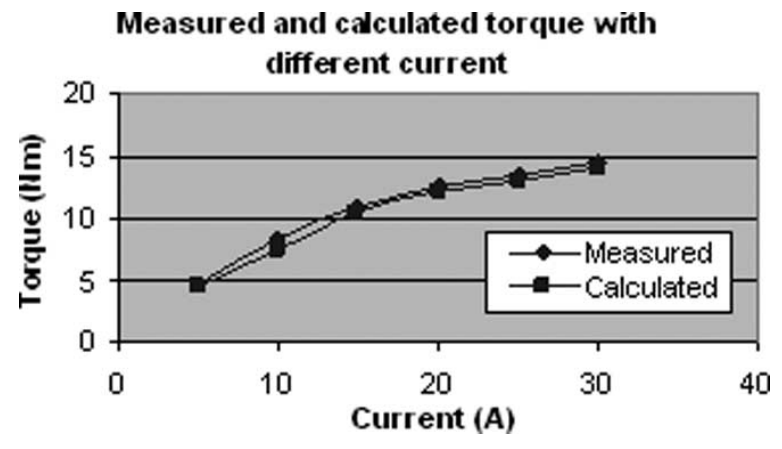

Fig. 7. Comparison of measured and calculated torque with different currents.

operating conditions, including sudden short circuits. It is also assumed that the machines are cooled adequately such that the temperature rise is not over the magnet temperature limit, which means forced cooling is required for larger output machines.

The current density in the stator windings is kept constant at $4 \times 10^{6} \mathrm{~A} / \mathrm{m}^{2}$ for all the designs. The three-phase windings are $\mathrm{Y}$ connected. As the power output gets larger, multiple strands of copper wire are used in the stator coil. In actuality, the number of strands is usually increased while decreasing the wire diameter so that forming the conductors in the slots and the end turns becomes easier.

As the machines have multipole construction at low speed, fractional slot and short pitch windings have to be applied to decrease the harmonics.

The magnets used are sintered $\mathrm{NdFeB}$ for all the machines with remanence of $1.0 \mathrm{~T}$ and coercivity of $750 \mathrm{kA} / \mathrm{m}$. These values correspond to the working temperature and the magnet temperature coefficients are considered in the designs.

The generator design is the result of the comprehensive application of machine theory, design and test knowledge, and experience. Many factors will influence the accuracy of the design, which make the design complicated and time consuming, especially for new and special constructions. Some factors may be derived analytically with the addition of experience to modify the coefficients. Other factors cannot be derived analytically. In those cases, numerical computation must be applied. In this paper, some critical coefficients, such as magnetic field waveform coefficient, leakage coefficient, and armature reaction coefficient, are first derived analytically and then numerically modified using the finite-element method (FEM). For example, the magnetic field waveform coefficient

$$
K_{f}=\frac{B_{\delta 1}}{B_{\delta}}
$$

where $B_{\delta}$ is the amplitude of air gap flux density and $B_{\delta 1}$ is the fundamental amplitude of air gap flux density. The waveform of the magnetic field in the air gap can be computed by FEM, and then Fourier analysis applied to obtain the fundamental amplitude. In this way, some curves and look-up tables are introduced by FEM computations to make the future design more convenient. All the designs are optimized to get the highest torque density and efficiency.

To verify the accuracy of the analytical model, two experimental machines are designed first to provide benchmarks. One

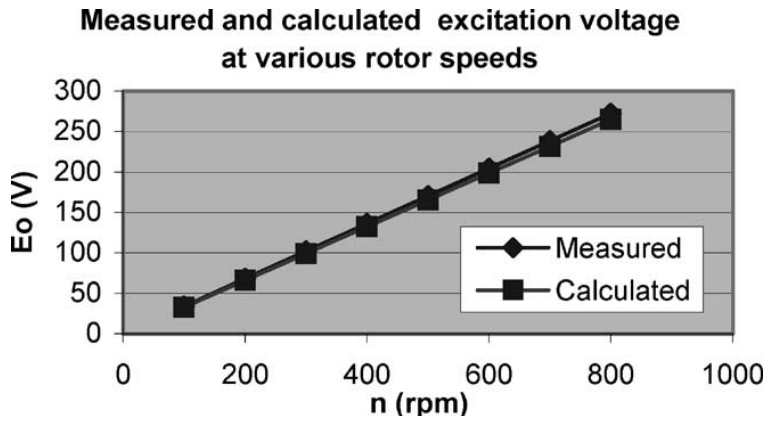

Fig. 8. Comparison of measured and calculated rms value of fundamental excitation voltage at various rotor speeds.

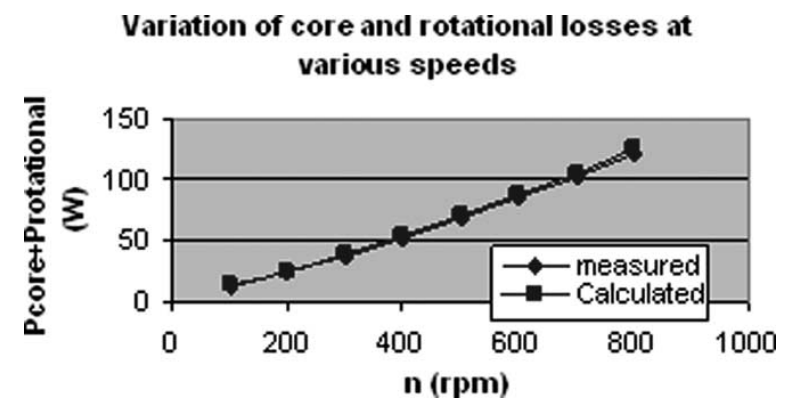

Fig. 9. Variation of core and rotational losses with speed.

is the axial-flux PM servomotor with 16 poles, one rotor, and two stators. Fig. 7 shows the designed and tested results. This work proves that the magnetic circuit calculations with axialflux configurations are accurate.

Another is the conventional inner-rotor radial-flux PM wind generator with output power of $3.5 \mathrm{~kW}, 750 \mathrm{r} / \mathrm{min}, 8$ poles, and 36 slots, which is a commercial product. The comparison of resulting rms value of the fundamental excitation voltage between calculation and measurement is shown in Fig. 8. The variation of calculated and measured core and rotational losses with speed is illustrated in Fig. 9.

From the results presented here, it can be seen that good agreement exists between calculated and measured values, which validates the design equations.

\section{RESULTS}

The results of the comparison are given in graphical form and will be explained in the following sections.

\section{A. Torque/Volume and Torque/Weight Versus Power}

Torque per volume or torque density is chosen because it is independent of the choice of rotational speed. This is true only up to a certain speed, which is far above the typical speeds found in wind turbines. The torque/volume is defined as the ratio of the developed torque of the generator to the active volume of the machine. The active volume includes the volume of magnets, copper conductor, stator teeth, and yoke.

Fig. 10 illustrates the results for direct-drive stand-alone machines. Type-D double-rotor slotted axial-flux configurations have the highest torque density, while Types E and F singlesided machines with stator balance and rotor balance have the lowest values. Type-B radial-flux machines with outer rotor 


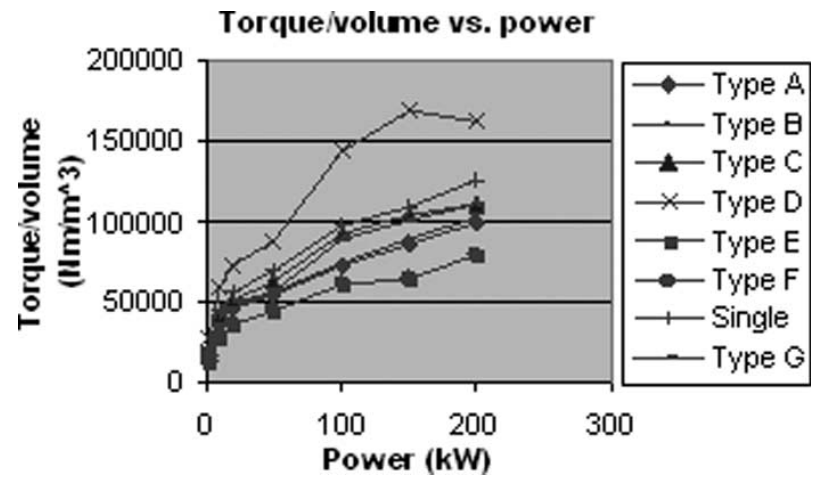

Fig. 10. Torque per volume versus power for direct-driven machines.

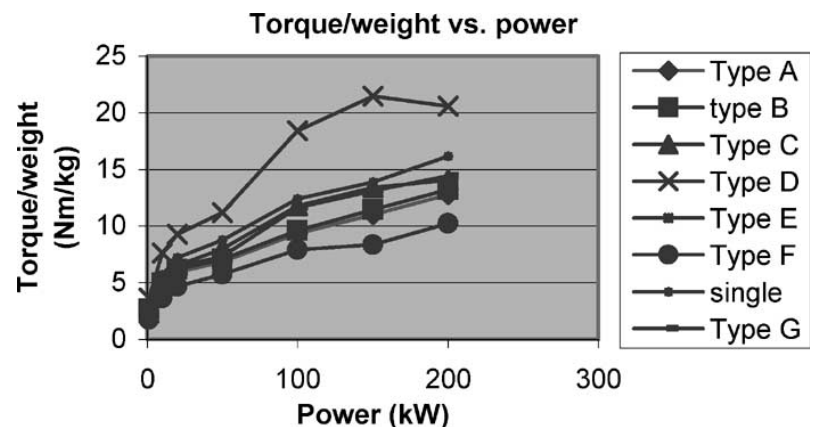

Fig. 11. Torque per weight versus power for direct-driven machines.

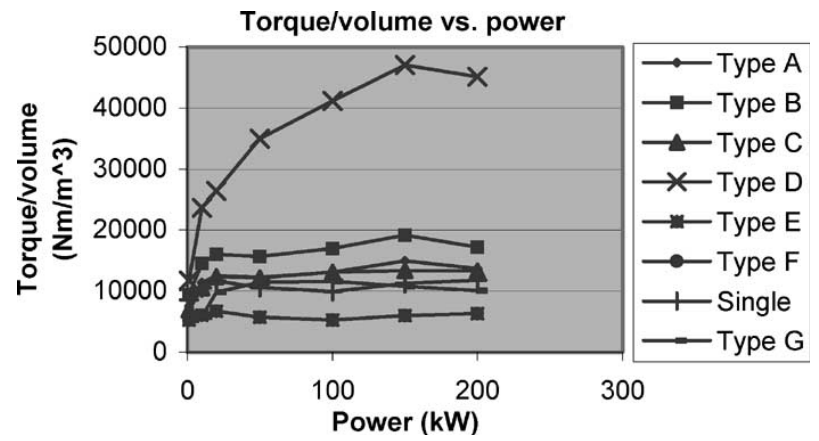

Fig. 12. Torque per volume versus power for high-speed machines

are better than Type-A, the conventional inner-rotor radialflux machines, due to the enlarged periphery of the outer-rotor drum. The torque density for Type-G axial-flux construction with toroidal winding is between the double side axial-flux configurations and single side axial-flux configurations with force balance. Compared to axial-flux constructions, radial-flux machines are similar to the Torus machine in torque density. The torque/weight comparison has similar results to those mentioned above, as shown in Fig. 11.

Figs. 12 and 13 show the comparison of torque per volume and torque per weight for high-speed machines. Type-D has the highest value, and Types $\mathrm{E}$ and $\mathrm{F}$ have the lowest ones. However, the torque density for double-stator slotted axialflux construction is less than that of the outer-rotor radial-flux construction and close to that of the inner-rotor construction. This is because the axial length has to be enlarged to provide a path for magnetic flux as the number of poles in the gridconnected machine is decreased.

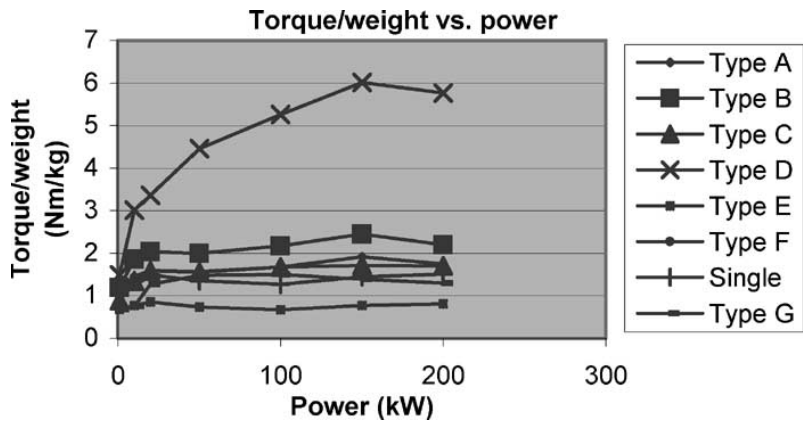

Fig. 13. Torque per weight versus power for high-speed machines.

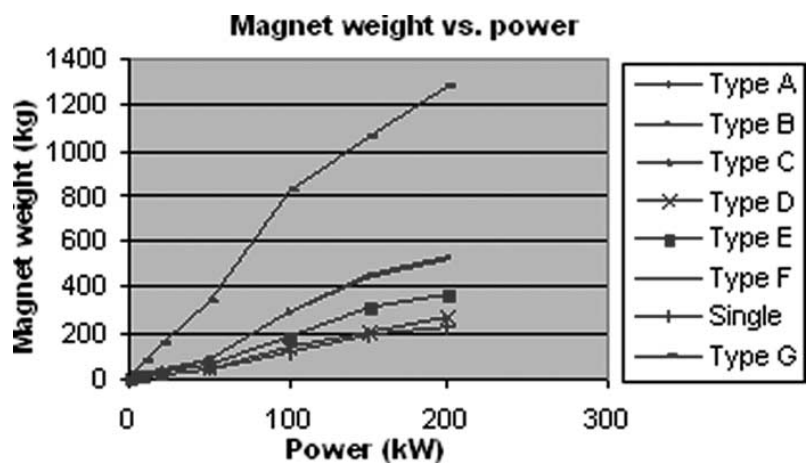

Fig. 14. Magnet weight versus power for direct-driven machines.

It can be seen from Figs. 10-13 that the torque densities for direct-drive machines are much better than that of highspeed machines with gear boxes, which means that low-speed multipole PM wind generators are more suitable than highspeed machines with gear boxes.

\section{B. Magnet Weight Versus Power}

Fig. 14 shows the variation of the required magnet weight for direct-drive machines. Apparently, Type-G, the axial-flux construction with toroidal winding, requires maximum magnet weight, as an additional air gap is needed to accommodate the stator winding. The double-sided axial-flux topologies can make the best use of the magnets. The outer-rotor radial-flux construction uses less magnet material than the inner-rotor radial-flux construction. For all axial-flux configurations except the Torus machine, the use of magnets is better than that for radial-flux constructions. As the price of $\mathrm{NdFeB}$ magnet is still high, axial-flux slotted wind generator designs can reduce magnet cost. Fig. 15 shows the magnet weight change as a function of power rating for high-speed machines. For the same output power, this group of machines uses less magnet, as the speeds of these machines are much higher. The most important discrepancy between Figs. 14 and 15 is that the single-sided axial-flux construction uses more magnet than the radial-flux construction.

\section{Copper Weight Versus Power}

Fig. 16 shows the variation of the required copper weight for direct-drive machines. Maximum copper is required by inner-rotor radial-flux machine. This is due to the fact that 


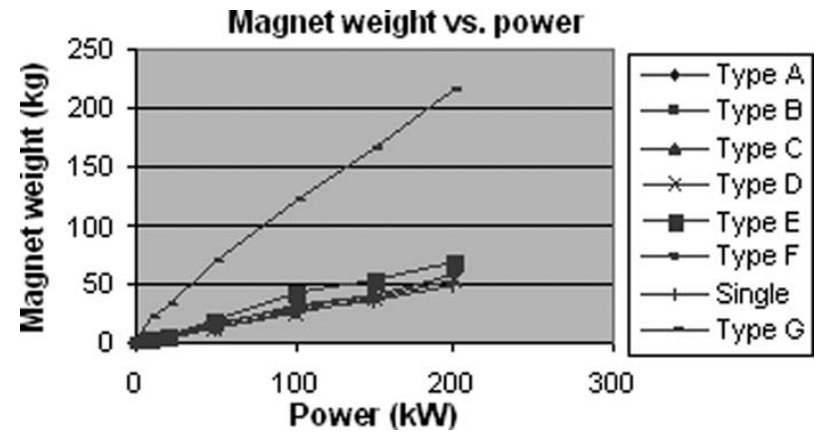

Fig. 15. Magnet weight versus power for high-speed machines.

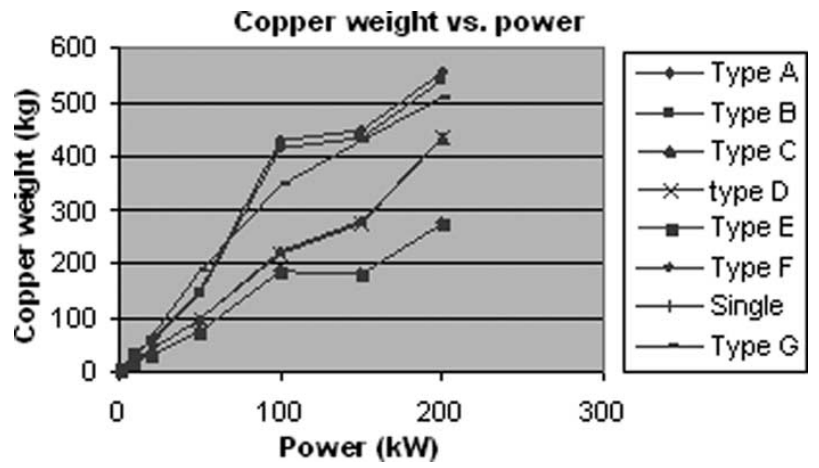

Fig. 16. Copper weight versus power for direct-driven machines.

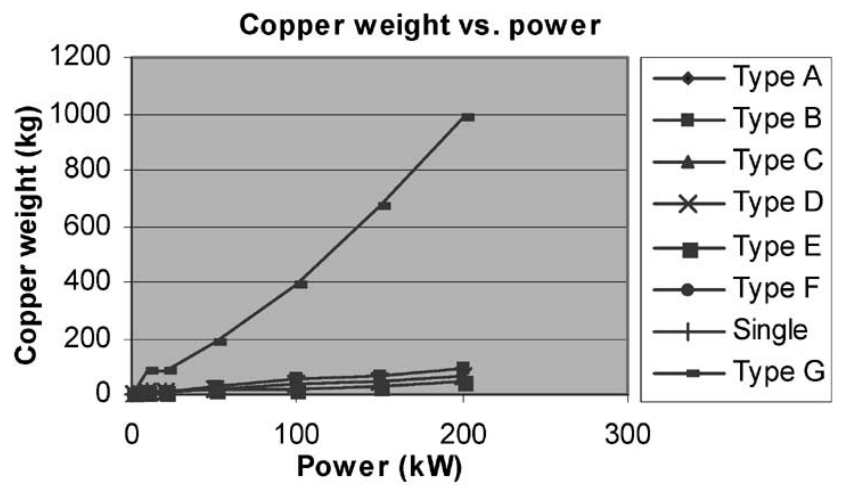

Fig. 17. Copper weight versus power for high-speed machines.

the end length in the radial-flux construction is longer than that in the axial-flux construction. The single-sided axial-flux configuration uses the least copper. The Torus machine uses more copper than double-sided axial-flux machines, as the air gap flux density in the Torus machine is less than that of axial-flux slotted machines. Fig. 17 shows the variation of the required copper weight for high-speed machines. In this situation, the use of copper in the Torus machine is much more than those used by other topologies. This means that the Torus machine can only be used in multipole configurations, as the magnetic path is shorter in these cases, resulting in the end turn length being shorter.

\section{Lamination Weight Versus Power}

Fig. 18 shows the variation of the required lamination weight for direct-drive machines. The maximum value of lamination

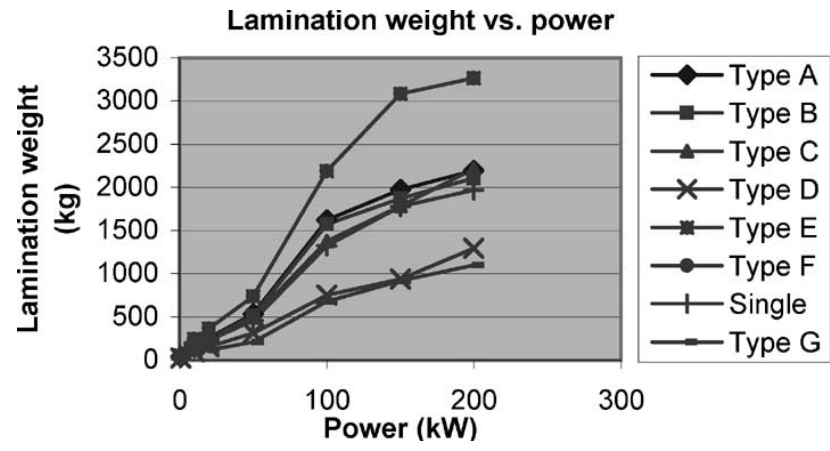

Fig. 18. Lamination weight versus power for direct-driven machines.

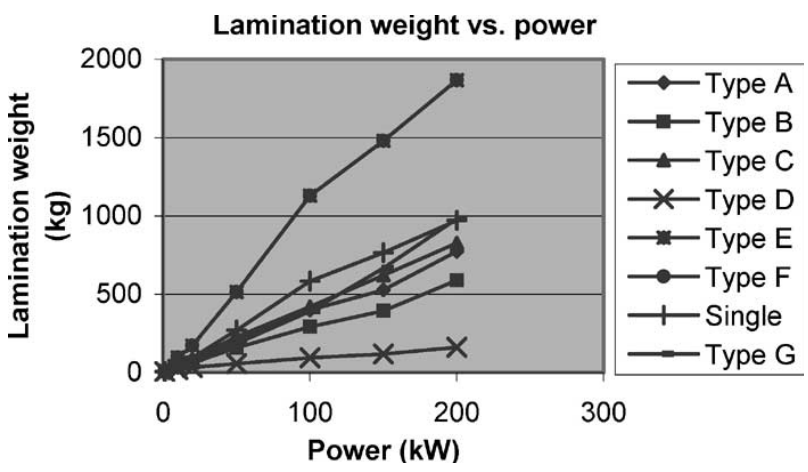

Fig. 19. Lamination weight versus power for high-speed machines.

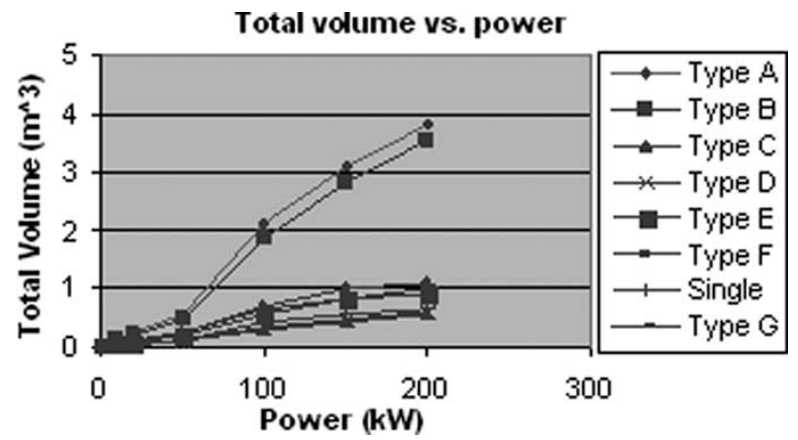

Fig. 20. Total volume versus power for direct-driven machines.

is used by single-sided axial-flux machines. The Torus machine uses the minimum amount of laminations because of the absence of stator teeth. The double-sided axial-flux slotted constructions make better use of the laminations than the radialflux constructions. Fig. 19 shows the variation of the required lamination weight for high-speed machines. The increase of lamination use for axial-flux configurations in this case is because an enlarged axial length is needed to provide a path for the magnetic flux in the stator yoke, as the pole number is lower.

\section{E. Total Volume Versus Power}

Fig. 20 shows the variation of the total volume for directdrive machines. The radial-flux configurations take the maximum space. The double-stator axial-flux slotted machine requires the least space, as in this construction no rotor back yoke is needed and the axial length is very short. Fig. 21 shows the variation of the total volume for high-speed machines. In this case, single-sided axial-flux constructions need more 


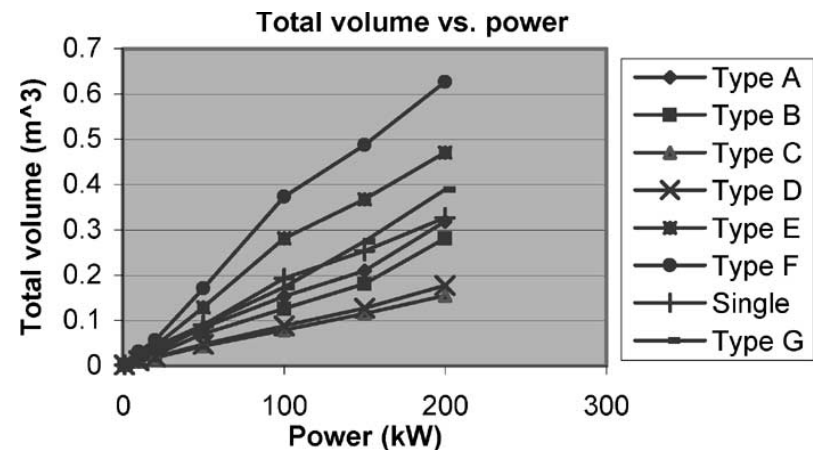

Fig. 21. Total volume versus power for high-speed machines.

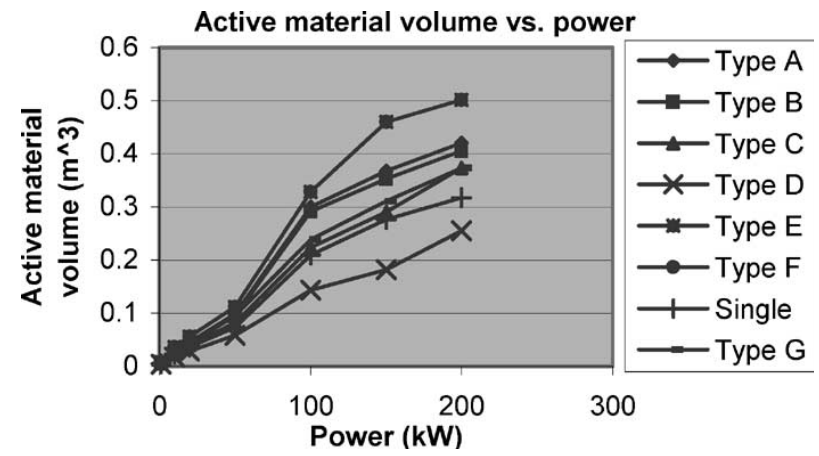

Fig. 22. Active material volume versus power for direct-driven machines.

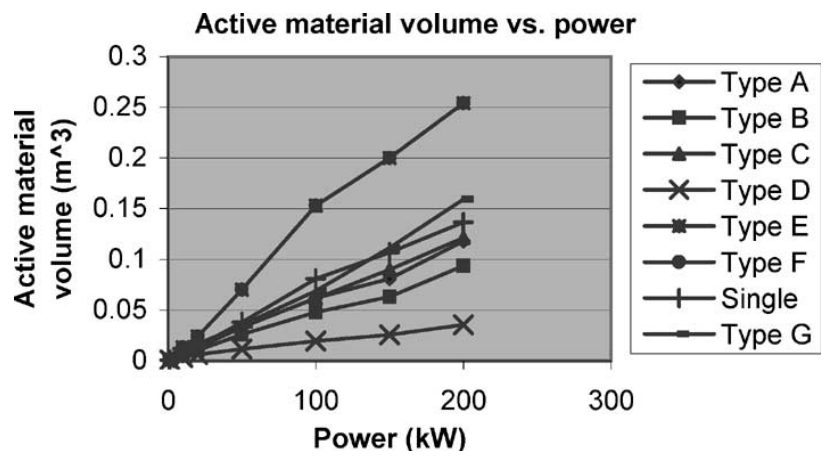

Fig. 23. Active material volume versus power for high-speed machines.

room due to the lower pole number and the increased axial length.

\section{F. Active Material Volume Versus Power}

Fig. 22 shows the variation of the active material volume for direct-drive machines. The maximum active materials are spent by single-sided axial-flux machines. The double rotor axial-flux slotted machine uses the minimum amount of active materials, as the stator back of yoke in this construction is only used for mechanical strength and is very thin. The Torus machine uses almost the same active materials as those used by the double-stator axial-flux machine but less than that used by radial-flux machines. Fig. 23 shows the variation of the active material volume for high-speed machines. The increase of the active material for the Torus machine in this case is because the enlarged axial length is needed to provide a path for magnetic flux in the stator yoke, as the pole number is lower here.

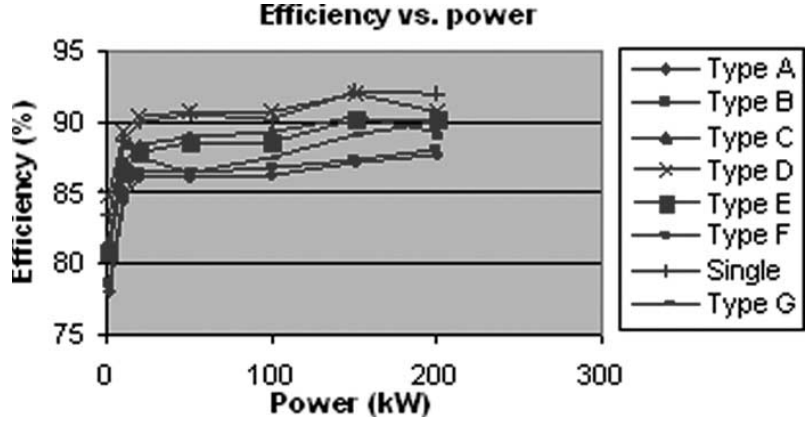

Fig. 24. Efficiency versus power for direct-driven machines.

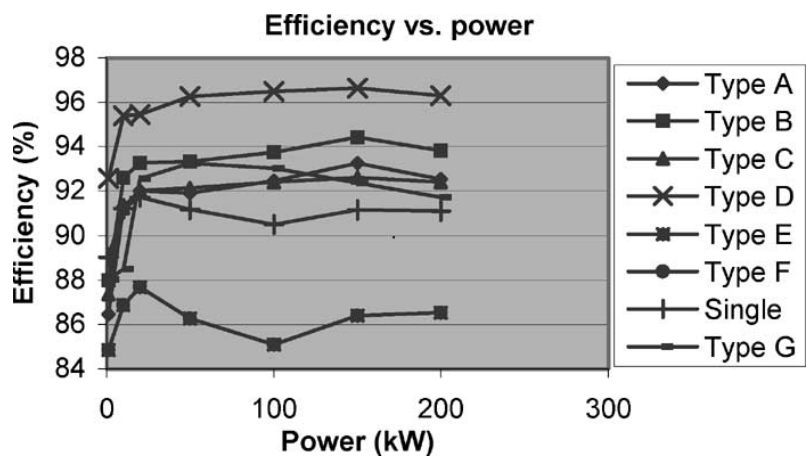

Fig. 25. Efficiency versus power for high speed machines.

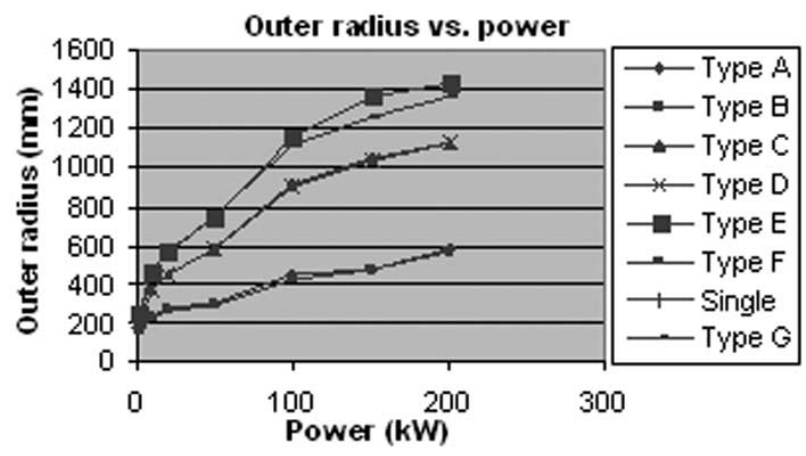

Fig. 26. Outer radius versus power for direct-driven machines.

\section{G. Efficiency Versus Power}

Fig. 24 shows the variation of efficiency for direct-driven machines. The highest efficiency exists in the double rotor axial-flux machine, as the iron loss in this construction is the least. The radial-flux configurations have the lowest efficiency. Apparently, the larger output power has higher efficiency. Fig. 25 shows the variation of efficiency for high-speed machines. In this case, the single-sided axial-flux constructions are not efficient due to the lower pole number and the increased axial length.

\section{H. Outer Radius Versus Power}

Fig. 26 shows the variation of outer radius for direct-drive machines. The single-sided axial-flux constructions need the largest outer radius, as there is only one stator in this construction. The radial-flux configurations have the minimum outer radius. This is identical to other machine designs. 
Total length vs. power

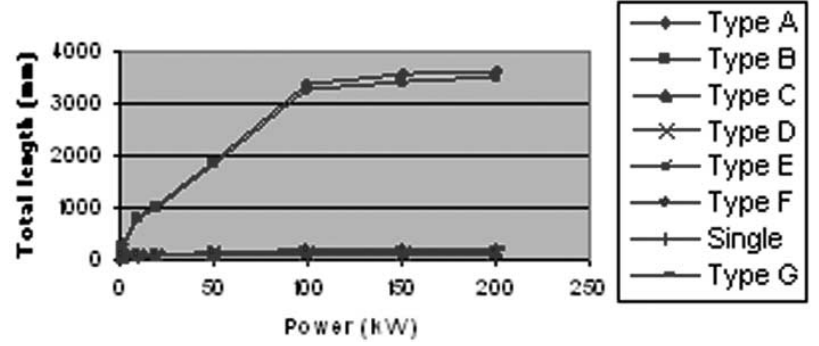

Fig. 27. Total length versus power for direct-driven machines.

\section{Total Length Versus Power}

Fig. 27 shows the variation of total length for direct-drive machines. It is very clear that radial-flux constructions have a much longer axial length than axial-flux constructions, especially for multipole machines. The axial length for axial-flux machines is much shorter than the radius. That is why these configurations are referred to as pancake machines.

\section{CONCLusion}

From the data presented in previous sections, it is inferred that axial-flux slotted machines have a smaller volume for a given power rating, making the power density very high. This is true for all the investigated power ratings. However, it should be mentioned that as the power rating increases and the outer radius becomes larger, the mechanical dynamic balance must be taken into consideration for axial-flux machines.

The two-sided axial-flux configuration is superior to the onesided axial-flux configuration. However, one-sided constructions use less copper and have a lower conductor loss. This kind of construction is also simple in construction.

For all of the comparisons, the outer-rotor radial-flux construction is superior to the inner-rotor radial-flux construction. The former also has advantages such as ease of installation and cooling. Therefore, the outer-rotor construction is more suitable to be applied in wind energy systems.

The Torus construction is simple, and many researches have chosen this configuration. However, this construction requires more magnet weight because of the presence of the additional air gap for accommodating stator windings. As the power rating increases, both the air gap and air gap reluctance due to the magnet and winding become larger. Therefore, this construction is more suitable for low power rating wind generators.

For most of the comparisons, the low-speed constructions are superior to high-speed constructions, which means that multipole permanent magnet (PM) generators are preferred in the application of small gearless low-speed wind systems.

\section{REFERENCES}

[1] E. Spooner and A. C. Williamson, "Direct coupled, permanent magnet generators for wind turbine applications," Proc. IEE-Electr. Power Appl., vol. 143, no. 1, pp. 1-8, Jan. 1996.

[2] L. Soderlund and J.-T. Eriksson, "A permanent-magnet generator for wind power applications," IEEE Trans. Magn., vol. 32, no. 4, pp. 2389-2392, Jul. 1996.

[3] J. Chen, C. V. Nayar, and L. Xu, "Design and finite-element analysis of an outer-rotor permanent-magnet generator for directly coupled wind turbines," IEEE Trans. Magn., vol. 36, no. 5, pp. 3802-3809, Sep. 2000.
[4] M. R. Dubois, H. Polinder, and J. A. Ferreira, "Comparison of generator topologies for direct-drive wind turbines," in Proc. Int. Conf. Electrical Machines (ICEM), Manchester, U.K., 1992, pp. 761-765.

[5] K. J. Binnsand and D. W. Shimmin, "Relationship between rated torque and size of permanent magnet machines," Proc. IEE-Electr. Power Appl., vol. 143 , no. 6 , pp. 417-422, Nov. 1996.

[6] E. Muljadi, C. P. Butterfield, and Y.-H. Wan, "Axial-flux modular permanent-magnet generator with a toroidal winding for wind-turbine applications," IEEE Trans. Ind. Appl., vol. 35, no. 4, pp. 831-836, Jul./Aug. 1999.

[7] S. Huang, J. Luo, F. Leonardi, and T. Lipo, "A comparison of power density for axial flux machines based on general purpose sizing equations," IEEE Trans. Energy Convers., vol. 14, no. 2, pp. 185-191, Jun. 1999.

[8] B. J. Chalmers, W. Wu, and E. Spooner, "An axial-flux permanentmagnet generator for a gearless wind energy system," IEEE Trans. Energy Convers., vol. 14, no. 2, pp. 251-257, Jun. 1999.

[9] A. J. G. Westlake, J. R. Bumby, and E. Spooner, "Damping the powerangle oscillations of a permanent-magnet synchronous generator with particular reference to wind turbine applications," Proc. IEE-Electr. Power Appl., vol. 143, no. 3, pp. 269-280, May 1996.

[10] E. Spooner, A. C. Williamson, and G. Catto, "Modular design of permanent-magnet generators for wind turbines," Proc. IEE-Electr. Power Appl., vol. 143, no. 5, pp. 388-395, Sep. 1996.

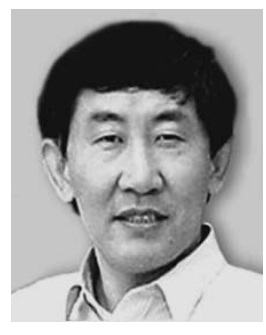

Yicheng Chen received the M.S. degree in electrical engineering from Shenyang University of Technology, Shenyang, China, in 1984, and the Ph.D. degree in electrical engineering from Clarkson University, Potsdam, NY, in 2004.

He was a Professor of Electrical Engineering at Shenyang University of Technology. He is currently a Senior Commissioning Engineer with Siemens Energy and Automation, Inc., Alpharetta, GA. His research and working experience includes electrical machine design and motor drives.

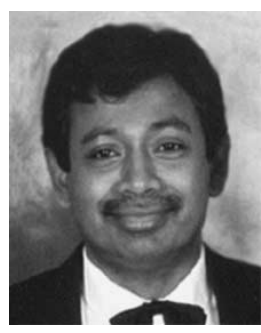

Pragasen Pillay (S'84-M'87-SM'92-F'05) received the B.S. and M.S. degrees from the University of KwaZulu-Natal, South Africa, in 1981 and 1983, respectively, and the Ph.D. degree from Virginia Polytechnic Institute and State University, Blacksburg, in 1987, while funded by a Fulbright Scholarship.

From January 1988 to August 1990, he was with the University of Newcastle upon Tyne, England. From August 1990 to August 1995, he was with the University of New Orleans. Since 1999, he has been an Adjunct Professor at the University of Cape Town, South Africa. $\mathrm{He}$ is currently a Professor in the Department of Electrical and Computer Engineering, Clarkson University, Potsdam, NY, where he holds the Jean Newell Distinguished Professorship in Engineering. His research and teaching interests are in modeling, design and control of electric motors and drives for industrial and alternate energy applications and power quality.

Dr. Pillay is a member of the IEEE Power Engineering, IEEE Industry Applications, IEEE Industrial Electronics, and IEEE Power Electronics Societies. $\mathrm{He}$ is a member of the Electric Machines Committee, past Chairman of the Industrial Drives Committee within the IEEE Industry Applications Society, and past Chairman of the Induction Machinery Subcommittee in the IEEE Power Engineering Society. He is a Fellow of the IEE, England, and a Chartered Electrical Engineer. He is also a member of the Academy of Science of South Africa. He has organized and taught short courses in electric drives at the Annual Meeting of the IEEE Industry Applications Society.

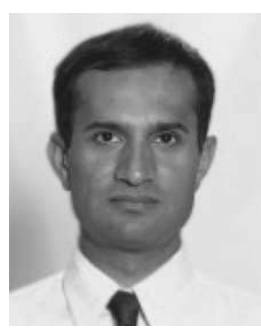

Azeem Khan (S'02) received the B.S. and M.S. degrees in electrical engineering from the University of Cape Town, Rondebosch, South Africa, where he is currently working toward the Ph.D. degree in electrical engineering.

His research interest includes the design and control of permanent-magnet (PM) machines. 